\title{
Effect of thermodynamic database selection on the estimated aqueous uranium speciation
}

\section{Xinyu Wang ${ }^{1}$, Zeming Shi ${ }^{2}$, David G. Kinniburgh $^{3}$}

${ }^{1}$ [Deparrment of Geochemistry, Chengdu University of Technology, Chengdu, Sichuan, China,

E-mail: wangxinyu2014@cdut.edu.cn]

${ }^{2}$ [Deparrment of Geochemistry, Chengdu University of Technology, Chengdu, Sichuan, China,

E-mail:shizm@cdut.edu.cn]

${ }^{3}$ [Formerly British Geological Survey, Wallingford, Oxfordshire OX10 8BB, UK,

E-mail: david@phreeplot.org]

Comparisons of the completeness and accuracy of the thermodynamic databases for aqueous uranyl complexes involving common inorganic anions $\left(\mathrm{OH}^{-}, \mathrm{SO}_{4}{ }^{2-}, \mathrm{PO}_{4}{ }^{3-}\right.$, $\left.\mathrm{CO}_{3}^{2-}, \mathrm{SO}_{4}^{2-}, \mathrm{Cl}^{-}, \mathrm{F}^{-}, \mathrm{I}^{-}, \mathrm{Br}^{-}\right)$and some organic ligands have been made between a number of publicly-available thermodynamic databases (MINTEQ, LLNL, WATEQ4F, ThermoChimie, NEA-TDB, and PSI/Nagra).

Although the stability of the stronger bioavailable uranyl-phosphate complexes remains uncertain, the available thermodynamic data suggests that the proportion and toxicity of most uranyl-phosphate complexes will be negligible when the $\mathrm{pH}$ exceeds 8.5 and the inorganic phosphate concentration (as $\mathrm{PO}_{4}{ }^{3-}$ ) is less than $2 \mathrm{mg} / \mathrm{L}$.

\section{Detailed information:}

Wang Xinyu, Shi Zeming, David G. Kinniburgh et al. Effect of thermodynamic database selection on the estimated aqueous uranium speciation, Journal of Geochemical Exploration 204 (2019) 33-42. 